\title{
Frequency Effects in Auditory Word Recognition: The Case of Suffixed Words
}

\author{
Fanny Meunier and Juan Segui \\ Centre National de la Recherche Scientifique and Université René Descartes, Paris, France
}

\begin{abstract}
This research studied the role of surface and cumulative word frequency in the processing and representation of morphologically complex suffixed words. Experiment 1 showed that auditory lexical decision times to suffixed words were influenced by their surface frequency. Experiments 2 and 3 showed a cumulative root frequency effect for high- and low-surface-frequency suffixed words. Experiment 4 demonstrated that lexical decision times for these words varied as a function of their position in their morphological family. These results support a view whereby suffixed words belonging to a given morphological family share the same lexical entry. Within a lexical entry, suffixed words belonging to the same family are organized on the basis of their surface frequency and compete with one another. ๑) 1999 Academic Press

Key Words: morphology; lexical decision task; suffixed words.
\end{abstract}

The word-frequency effect is one of the most robust findings in the field of visual word recognition. Indeed, the frequency with which a word occurs in printed language is a consistent predictor of performance in a variety of tasks used to study visual word recognition. In an early study, Howes and Solmon (1951) showed that the visual recognition threshold for tachistoscopically presented words is a function of the logarithm of their frequency. Subsequently, this correlation has been observed in a large variety of experimental tasks such as tachistocopic report (Humphreys, Besner, \& Quinlan, 1988; Jacoby \& Dallas, 1981), picture naming (Oldfield \& Wingfield, 1965), word naming (Forster \& Chambers, 1973), lexical decision (Forster, 1973; Rubenstein, Garfield, \& Millikan, 1970; Segui, Mehler, Frauenfelder, \& Morton, 1982),

This research was supported by the French Ministry "de l'enseignement supérieur et de la recherche." This article is based on a part of the first author's doctoral dissertation (Université René Descartes-Paris V). Arthur Samuel and two anonymous reviewers made very helpful comments on an earlier version of this article. We also thank Sami Boudelaa, Rhodri Cusack, Ludovic Ferrand, Mike Ford, and Gareth Gaskell for their help and suggestions.

Address correspondence and reprint requests to Fanny Meunier, Medical Research Council, Cognition and Brain Sciences Unit, 15 Chaucer Road Cambridge CB2 2EF, United Kingdom. E-mail: fanny.meunier@mrc-cbu.cam. ac.uk. and the reading of word lists (Geffen, Stierman, \& Tildesley, 1979).

Different theoretical accounts for this effect have been proposed. For example, Forster and Chamber's (1973) search model of lexical access assumes that word frequency affects the organization of the search process. In this model, lexical access involves a search through a subsection of the lexicon based on partial lexical information (e.g., syllable or morpheme). Each subsection or bin is organized by frequency, and lexical search is frequency ordered in that higher frequency words are checked against the input before lower frequency words. Low-frequency words are therefore recognized more slowly than high-frequency words. An alternative model of lexical access, the logogen model (Morton, 1969, 1982), assumes a word-level representation in the form of word detectors or logogens for each word of the lexicon. The word-frequency effect is explained in this framework by assuming that logogens corresponding to high-frequency words have a higher initial resting level than those corresponding to low-frequency ones. A similar interpretation of the frequency effect is proposed by some connectionist models corresponding to variants of McClelland and Rumelhart's (1981) interactive-activation model. 
Although word frequency is a consistent predictor of performance in the visual modality, it is only recently that this effect has been studied in detail in the auditory modality. This is important given that specific properties of speech output prevent generalization of results collected from the visual modality to those obtained from the auditory modality. The two modalities are different in at least one important aspect: speech necessarily has a temporal component that is largely missing from the visual domain.

\section{THE FREQUENCY EFFECT IN THE AUDITORY MODALITY}

Early results concerning frequency effects in the auditory modality were obtained in the 1950s and 1960s. Howes (1957) found a correlation between the frequency of occurrence of a word and the signal-to-noise ratio necessary for the recognition of that word. Savin (1963) observed a tendency for common words to be perceived correctly at much lower speech-tonoise ratios than uncommon words, but proposed that the effect was not perceptual but related to a response bias (see also Broadbent, 1967; Morton, 1969; Pollack, Rubenstein, \& Decker, 1960). However, several researchers in the 1970 s reported differences between common and rare words that covary with their frequency of usage and make the interpretation of the previous results problematic. For instance, rare words are generally longer than more frequent ones (Landauer \& Streeter, 1973; Wright, 1979).

The absence of clear empirical data about the role of word frequency in the auditory modality during the 1970s may explain the fact that in the first model specifically constructed for spokenword recognition, the original version of the Cohort model (Marslen-Wilson \& Welsh, 1978), word frequency was not considered important. According to this and later versions of the model (Marslen-Wilson, 1987; Warren \& Marslen-Wilson, 1987), spoken words are recognized by a process that involves the continuous mapping of the sensory input onto representations of lexical forms. Based on the principle of maximal processing efficiency, the model states that each word is recognized at the first point after word onset at which it becomes uniquely distinguishable from all other words in the language beginning with the same sound sequence. This is called the uniqueness point (UP). During the recognition process, a set of word candidates is activated based on the initial sensory input. This set includes all the words in the language beginning with that initial sound sequence (the word-initial cohort). As more input is processed, only the word candidates that continue to match the incoming sensory input remain active. This process continues until a single word candidate is left that matches the input. From the point of view of this model, short and long words are not equal because most short words have their UP at or near their offset, whereas most long words can be recognized before their acoustic offset.

More recently, many studies have been done to test the frequency effect in the auditory modality. Tyler's (1984) finding that word frequency affects recognition in a gating task raised a problem for the first version of the Cohort model (Marslen-Wilson \& Welsh, 1978). This result, however, should be interpreted with caution because the effects may have arisen through some form of sophisticated guessing employed when stimulus information is limited. Two years later, however, Taft and Hambly (1986) obtained a word-frequency effect using the auditory lexical decision task. They demonstrated a frequency effect when high- and low-frequency words were matched for UP. The presence of a frequency effect in auditory lexical decision was replicated by several authors (Connine, Mullenix, Shernoff, \& Yelen, 1990; Marslen-Wilson, 1990; Slowiaczeck \& Pisoni, 1986). However, mixed results were obtained with auditory repetition (Bates, Devescovi, Pizzamiglio, D’Amico, \& Hernandez, 1995; Connine et al., 1990; Marslen-Wilson, 1990). According to Connine et al. (1990) the absence of a frequency effect in the shadowing task may reflect the fact that word repetition can be conducted without lexical access. More recently, Connine, Titone, and Wang (1993) observed a word-frequency effect in a phoneme categorization task. Speech voicing 
continua were constructed so that one endpoint resulted in a high-frequency word and the other endpoint resulted in a low-frequency word (e.g., best-pest). The results demonstrated that ambiguous tokens were labeled in concordance with the high-frequency word. Finally, Ferreira, Henderson, Anes, Weeks, and McFarlane (1996) used a new technique called the "auditory moving window" in which subjects paced their way through spoken sentences divided into words or word-like segments, and their processing time for each segment was recorded. Ferreira et al. demonstrated that high-frequency words in spoken sentences required less time to be processed than low-frequency words.

The experimental work indicating the existence of a word-frequency effect in the auditory modality led Marslen-Wilson $(1987,1990)$ to incorporate in his model a mechanism that accounted for it. In the new version of the Cohort model, Marslen-Wilson assumed that words in a cohort have differing levels of activation according to their frequencies of occurrence. Words with higher activation levels take longer to eliminate from the cohort than words with lower activation levels, thus affording at least an initial advantage to high-frequency words.

The frequency effects reported in all the experiments mentioned above were found with short monomorphemic words. For at least two reasons, it is important to establish whether a frequency effect can be obtained for longer words. First, in contrast to most short words, a long word could become uniquely distinguishable from any other word in the language beginning with the same sound sequence much earlier than its offset. Second, and more importantly, long words are generally polymorphemic. According to Rey-Debove (1984), 80\% of French words listed in the dictionary "Robert Méthodique" are morphologically complex. Also, previous results obtained in visual word recognition indicated that the recognition of morphologically complex words could be affected not only by the frequency of their superficial word form but also by the cumulative frequency of all other members of the morphological family (see McQueen \& Cutler, 1998, for a review).

\section{THE FREQUENCY EFFECT FOR MORPHOLOGICALLY COMPLEX WORDS}

As noted above, two types of frequency estimate are relevant for a complex word: surface frequency and cumulative frequency. The former refers to the word's frequency of occurrence in the language as a free lexical item (e.g., the word fleuriste, "florist"). The latter refers to the sum of the frequency of the root plus all its affixed forms (fleuriste, "florist" + fleur, "flower" + fleurir, "to flower" + floral, "floral" + déflorer, "to deflower" + refleurir, "to flower again," and so on).

In the visual domain, several authors have shown that the recognition time for polymorphemic words is generally sensitive to both surface frequency and cumulative frequency (e.g., Burani \& Caramazza, 1987; Colé, Beauvillain, \& Segui, 1989; Holmes \& O’Regan, 1992; Taft, 1979). However, an asymmetry in the role of cumulative frequency was observed by Colé et al. (1989) using long words. In a lexical decision experiment they obtained a cumulative frequency effect for suffixed words but not for prefixed ones. These authors assumed that the asymmetry in the role of cumulative frequency for prefixed and suffixed words is related to the different sequential morphological organization of these two types of words (affix + root vs root + affix). Parsing procedures operating from left to right, the root is accessed first in the case of suffixed words as it is situated at the beginning of the word. The presence of a cumulative frequency for suffixed words implies that access to their lexical representations takes place via the representation of the root, which is sensitive to frequency of use. Since for prefixed words the processing of the root does not precede that of the full word form, the information derived from the root cannot be exploited on-line in lexical access.

\section{COMPLEX WORDS AND THE AUDITORY MODALITY}

On a "strict" left-to-right model such as the Cohort model (Marslen-Wilson, 1987; MarslenWilson \& Welsh, 1978), the information contained in the sensory input is continuously 
mapped onto representations in the mental lexicon, irrespective of whether the word is monomorphemic or morphologically complex. The lexicon is composed of full-form entries so words are accessed as complete units, whether or not they contain affixes. Even if this kind of model seems more likely in auditory than in visual presentation, prelexical decomposition has also been considered. For example, in the affix-stripping model proposed by Taft and Forster (1975; Taft, 1985), decomposition into stems and affixes is obligatory. Only when decomposition fails, as with pseudoprefixed words, will the system try to locate a full-form entry. This decomposition occurs prior to lexical access. Lexical access can proceed only via the stem because full-form affixed words do not have lexical entries.

Research by Taft, Hambly, and Kinoshita (1986) on derivationally prefixed English words extended to the auditory domain the types of theory and experiments that Taft and Forster had previously developed for visual word recognition (Taft, 1981, 1985; Taft \& Forster, 1975). Taft et al. (1986) conducted auditory and visual lexical decision experiments. Their materials were nonwords consisting of the four combinations of real and nonexistent prefixes (e.g., de, te-) with real and nonexistent stems (e.g., joice, jouse). They found that it took more time to make a nonword decision when the nonword carried a prefix than when it did not, and this difference increased when the item contained a real stem. Interestingly, the "stemness" factor had no effect for unprefixed nonwords. Taft et al. concluded that the stem played no role here because there was no prefix to strip off. These results are consistent with the affixstripping model (Taft, 1981, 1985; Taft \& Forster, 1975). The authors argued that access for a prefixed word is attempted first on the stem, and if that succeeds the listener must carry out additional processing to see if the prefix combines with the stem to make a legal word. However, there is a problem with these experiments in that data found for nonwords might not generalize to the processing of morphologically complex real words (see Henderson, 1985).

Tyler, Marslen-Wilson, Rentoul, and Hanney
(1988) attempted to test the prefix-stripping model of Taft and Forster (1975) by using derivationally prefixed real words. Tyler et al. (1988) compared the processing of free (monomorphemic) stems to that of prefixed words derived from this stem (e.g., build, rebuild). In their materials the UP of the prefixed word was always earlier than the UP of its stem. The decomposition model claims that both words should be recognized at the same segment (here /d/), the recognition point (RP) of the stem, and that RPs would be identical if they were measured from stem onset. A continuous model such as the Cohort model postulates no such relationship between the RPs because the words activate completely different cohorts; each word should be identified at its own UP (/d/ for build and /I/ for rebuild), so that the prefixed word should be identified before its stem (measured from the onset of the stem). Tyler et al. tested these competing claims in three experiments using three different tasks (gating, auditory lexical decision, and naming) with the same stimuli. None of these three experiments supported a decomposition account of lexical access: the presence of a prefix did not introduce any necessary delay into the access process. This result suggests that lexical access is not delayed until stem identification. Analogous results were obtained by Schriefers, Zwitserlood, and Roelofs (1991) in Dutch, using phoneme monitoring and gating tasks. However, Wurm (1997) recently reported results that suggest that a morphological decomposition process is applied to prefixed words that are highly semantically transparent and that have a high prefix likelihood (meaning that a high proportion of encountered words begin with letter string that are in fact truly prefixed, as with the prefix counter-). Laudanna, Burani, and Cermele (1994) also claimed that a word beginning with a prefix that has a high prefix likelihood is likely to be stored and accessed in decomposed form.

These experiments on morphologically complex words in auditory presentation used prefixed words because their aims were to test Taft's decomposition hypothesis. It is clear, given the directionality of the speech signal 
over time, that prefixed words are a particularly relevant test of this hypothesis. The results obtained lead us to reject Taft's hypothesis (but see Wurm, 1997) and partially support the idea of left-to-right processing of morphologically complex prefixed words. But is the same process involved during suffixed word identification? There is clear typological (Cutler, Hawkins, \& Guilligan, 1985) and experimental (Colé et al., 1989; Meunier, in press; Segui \& Zubizarreta, 1985) evidence that suffixes are treated differently from prefixes. Suffixed words derived from the same root are members of the same cohort and, as we have already shown, some models of auditory word recognition place particular importance on the first part of a word. Does the fact that the shared root is the first part of the signal processed by the system modify the process applied to the word? Our goal in the current study was to establish the roles of surface and cumulative frequencies during identification of auditorily presented suffixed words. An effect of surface frequency would indicate a role of the full word form, while an effect of cumulative frequency would indicate a role of morphological structure.

\section{EXPERIMENT 1}

In Experiment 1 we investigated the effect of surface frequency on the identification of pairs of suffixed words belonging to the same morphological family (and thus having the same cumulative frequency and the same cohort). This experiment tested if there is an effect of frequency on reaction times for auditorily presented long words and for words belonging to the same morphological family.

\section{Method}

Stimuli and design. Twenty pairs of suffixed words were selected so that the members of each pair shared the same root but differed in surface frequency, for instance démonstrateur, "demonstrator" and démonstration, "demonstration." It is important to note that the frequency and the identification point of the root are the same within each pair.

To select the experimental materials we pretested 60 pairs of derived words. Each pair was composed of one low-frequency word and one high-frequency one, according to the Trésor de la Langue Française (1971). Twenty-five participants were asked to decide which word of each pair was the more common. From the pretest materials we selected 20 pairs for which at least $80 \%$ of participants rated the more frequent word as more common. These stimuli were recorded at a normal speaking rate by a male native French speaker who was not familiar with the purpose of the study. We controlled word duration: high-frequency and low-frequency suffixed words had on average the same duration (781 ms; $t(19)<1$ for the difference). The high-surface-frequency suffixed words had an average of 2.9 syllables as compared to 3.0 for the low-surface-frequency suffixed words. The UPs of the two words within each pair were generally very close because most of the time their divergence point was also their UP; for example jardinER, "to garden" and jardinAge, "gardening" (the UP is in upper case). On average the UP was 6.6 phonemes into the word for suffixed words of high frequency and 6.8 phonemes for suffixed words of low frequency $[t(19)=1.31$, n.s. $]$. We also made the same comparison using a different cue: the length in milliseconds between the onset and the UP of the word. The high-frequency suffixed words had their UP on average $542 \mathrm{~ms}$ after the onset of word and low-frequency ones $556 \mathrm{~ms}$ ( $t(19)$ $<1)$.

Both items of each pair belonged to the same syntactic category. The mean surface frequency in the higher surface frequency condition was 31 compared to 2 for the lower surface-frequency condition. The frequency counts reported here are given per million, using the printed frequency counts of the Trésor de la Langue Française (1971), calculated on a 37.6million-word corpus. The items are listed in Appendix A.

Two experimental lists of 160 items each were constructed so that two derived words belonging to the same family were not presented in the same list. Each list was thus composed of 10 highsurface-frequency suffixed words, 10 low-surfacefrequency suffixed words, 60 filler words (20 prefixed words, such as rechanter, "to sing again" 
and 40 monomorphemic words, such as silence, "silence"), and 80 pronounceable nonwords, matched in length and morphological properties with the real words (20 "pseudosuffixed" nonwords, such as marcherie, 20 "pseudoprefixed" nonwords, such as décroner, and 40 nonwords that seem monomorphemic, such as solipre). The first 10 items of each list were filler items.

Procedure. Participants were tested individually in a quiet room. They were asked to decide, as quickly and as accurately as possible, whether each item they heard was a word by pressing one button and another button if it was not. The "yes" response was given with their preferred hand.

Items were presented auditorily via headphones using a DAT tape recorder. The interval between items was about $2 \mathrm{~s}$. The order of presentation was the same for each list with only experimental words changed. Response collection was controlled by the timer of a computer that had a tested accuracy of $\pm 1 \mathrm{~ms}$. The computer timer was started by a tone placed on the inaudible channel of the audiotape at the beginning of each word. Only response latencies that were associated with experimental words were recorded.

Participants. The participants in this and the following experiments took part in experiments in partial fulfillment of requirements for a psychology course of the University Paris V-René Descartes. Twenty students participated in the experiment. They were all native French speakers.

\section{Results and Discussion}

Analyses of variance (ANOVA) were conducted on the reaction time data. An alpha level of .05 was used for all statistical tests. We conducted analyses across both participants $(F 1)$ and items (F2). Reaction times were measured from the acoustic onset of the word. Reaction times longer than $1500 \mathrm{~ms}$ (3\% of all reaction times) were eliminated from the statistical analyses. Two items yielded more than $50 \%$ errors (littérateur and marieur) and were excluded from the analyses.

A problem for auditory word experiments is the choice of the point from which reaction time

\section{TABLE 1}

Mean Reaction Times and Error Rates as a Function of Surface Frequency for Suffixed Words Derived from the Same Root in Experiment 1

\begin{tabular}{lrr}
\hline & \multicolumn{2}{c}{ Surface frequency } \\
\cline { 2 - 3 } & High & Low \\
\hline RT (ms) & 925 & 1018 \\
SD & 119 & 132 \\
Errors $(\%)$ & 3 & 13 \\
\hline
\end{tabular}

is measured. The results of our experiments are reported as measured from word onset. The pattern of results was unchanged when reaction times were measured from the end of the word. It does not seem relevant to perform analyses from the UP because suffixed French words mostly have their UP on the first phoneme of the suffix. This means that the location of the UP does not differ between two suffixed words derived from a same root or between two suffixed words sharing the same suffix (pairs of words that constituted our stimuli).

High-frequency suffixed words were identified faster than low-frequency suffixed words derived from the same root (see Table 1). This surface frequency effect was significant across both participants $[F 1(1,19)=22.51 ; p<$ $.0001]$ and items $[F 2(1,17)=16.42 ; p<$ .0008]. Moreover, there were more errors for low-surface-frequency suffixed words than for high ones. This effect was significant across participants $[F 1(1,19)=8.35 ; p<.009]$ and items $[F 2(1,17)=8.7 ; p<.009]$.

In this experiment, we studied the role of surface frequency. It is known that this factor is important for lexical processing of monomorphemic words. The effect we observed for morphologically complex long words confirmed the importance of surface frequency: a higher frequency suffixed word was identified faster than a lower frequency one. In the second experiment, we examined the role of cumulative frequency for suffixed words. Assuming a left-toright parsing procedure, we hypothesize that suffixed words are accessed via their root mor- 
phemes. If so, we should observe a cumulative frequency effect for this type of word.

\section{EXPERIMENT 2}

Experiment 2 employed a similar design to Taft's (1979) study using the suffixed words from Experiment 1 of Colé et al. (1989). Words of each pair were matched on surface frequency and their cumulative frequencies were as different as possible. For example, jardinier, "gardener," with a surface frequency of 16 and a cumulative frequency of 197 was matched with policier, "policeman," with a surface frequency of 11 and a cumulative frequency of 64. If cumulative frequency affects the identification time of the word, then jardinier should have a shorter identification time than policier. This result will be interpreted as evidence for a role of morphemic structure in lexical processing. If we do not observe any difference between the identification times of jardinier and policier, then we could conclude that morphological structure does not influence word identification. To summarize, this experiment was identical to the previous one, except that surface frequency was held constant within pairs while cumulative frequency varied.

Furthermore, the derived pairs consisted of high-surface-frequency words or low-surfacefrequency words. As mentioned by Colé et al. (1989), in most previous studies conducted on the effect of cumulative frequency (Andrews, 1986; Burani \& Caramazza, 1987), the affixed words were low-frequency words. It was implicitly assumed that a decomposition procedure is more likely with rare words than with more frequent ones. The access to the latter could be more direct and related primarily to their surface frequency. According to this hypothesis, a cumulative frequency effect should be observed only for low-frequency suffixed words.

\section{Method}

Stimuli, design, and procedure. The word stimuli conformed to a factorial manipulation of cumulative root frequency (high or low) and surface frequency (high or low). Twenty pairs of suffixed words were selected. The members of each pair were strictly matched on surface frequency, but one member had a higher cumulative root frequency than the other.

These experimental pairs were divided into two sets according to their surface frequency, high $(18)$ or low $(<1)$. The mean cumulative root frequencies (per million) were 184 for words with high surface frequency and high cumulative frequency, 125 for words with high surface frequency and low cumulative frequency, 129 for words with low surface frequency and high cumulative frequency, and 9 for words with low surface frequency and low cumulative frequency. Suffixed words within each pair shared the same suffix. All experimental words were trisyllabic, and their lengths were comparable (713 ms for words with high surface frequency and high cumulative frequency, $723 \mathrm{~ms}$ for words with high surface frequency and low cumulative frequency, 753 $\mathrm{ms}$ for words with low surface frequency and high cumulative frequency, and $746 \mathrm{~ms}$ for words with low surface frequency and low cumulative frequency); none of these differences was significant. The experimental items are presented in Appendix B.

Two experimental lists were constructed. Each list was composed of all experimental words (20 high-cumulative-frequency suffixed words and 20 low-cumulative-frequency suffixed words), 130 filler words (of which 40 were prefixed words such as déchiffrer, "to decode" and 90 were monomorphemic words such as progrès, "progress"), and 178 nonwords that were, as in the first experiment, pronounceable and matched in length and morphological properties with real words of the list (40 "pseudosuffixed" nonwords such as gabotion, 40 "pseudo-prefixed" such as démircler, and 98 "pseudo-monomorphemic" such as crédate). Some nonwords began with a legitimate root, as fination, to avoid strategic effects.

All experimental words were presented in each list because none was derived from the same root. The order of presentation of experimental words was counterbalanced in two different lists. For example, if jardinier was in position 15 in the first list and policier in position 110, then in the second list jardinier was in 


\section{TABLE 2}

Mean Reaction Times and Error Rates as a Function of Cumulative Frequency and Surface Frequency for Derived Suffixed Words in Experiment 2

\begin{tabular}{crr} 
Surface & \multicolumn{2}{c}{ Cumulative frequency } \\
\cline { 2 - 3 } frequency & High & Low \\
\hline High & & \\
RT (ms) & 865 & 914 \\
SD & 98 & 117 \\
Errors (\%) & 2 & 2 \\
Low & & \\
RT (ms) & 979 & 983 \\
SD & 126 & 114 \\
Errors (\%) & 8 & 12 \\
\hline
\end{tabular}

position 110 and policier in position 15. Fillers and nonwords had the same position in the two lists. We also gave participants 12 examples of nonwords before the experimental list, after which the participant had a practice set containing 10 words and 10 nonwords. Then the experimental list started with 10 fillers.

Participants. Twenty-eight students from the same population as Experiment 1 took part in the experiment.

\section{Results and Discussion}

Response times higher than $1500 \mathrm{~ms}$ (1\% of all reaction times) were eliminated from the statistical analyses. It can be seen from Table 2 that suffixed words with higher cumulative frequency were identified faster than words of low cumulative frequency. This effect was significant in the participant $[F 1(1,27)=6.15 ; p<$ $.02]$ but not in the item analysis $[F 2(1,18)=$ 1.22 ; n.s.].

There was a main effect of surface frequency: high-surface-frequency words were recognized faster than low-surface-frequency words $[F 1(1$, $27)=92.58, p<.0001 ; F 2(1,18)=11.6, p<$ $.003]$. Moreover, the interaction between these two factors was significant by participants $[F 1(1,27)=7.86, p<.01]$ but not by items $[F 2(1,18)<1]$.

To clarify these effects we carried out planned comparisons ( $t$ tests) to find out if there was an effect of cumulative frequency for each level of surface-frequency suffixed words. The pattern observed with these analyses was clear. The effect of cumulative frequency for highsurface-frequency words was significant by participants $[t 1(27)=4.13, p<.0003]$ and by items $[t 2(9)=2.23, p<.05]$. For low-surfacefrequency suffixed words, there was no significant effect of cumulative frequency $[t 1<1$; $t 2<1$ ].

The error analyses showed more errors for low-surface-frequency words than for high-frequency ones. This effect of surface frequency was significant by participants $[F 1(1,27)=$ $16.35, p<.0005]$ and by items $[F 2(1,18)=$ $5.66, p<.03$ ]. However, no effect of cumulative frequency was observed $[F 1<1 ; F 2<1]$ and there was no interaction between the two factors $[F 1(1,27)=1.13$, n.s.; $F 2<1]$.

The results of this experiment confirm the presence of a surface frequency effect for suffixed words observed in our first experiment. Even when familiarity was not controlled, a surface frequency effect appeared. The observation of an effect of cumulative frequency only for high-surface-frequency suffixed words is not consistent with previous experimental findings in the visual modality. In fact, most of the experiments done in this field show a cumulative frequency effect only for suffixed words that have a low surface frequency (Bradley, 1979; Burani \& Caramazza, 1987). However, Colé et al. (1989) observed a cumulative frequency effect for low-surface-frequency suffixed words and high ones. Our results, therefore, go against all results previously observed and also against all models that propose two routes depending on the surface frequency of the word. However, we argue that we observed a cumulative frequency effect only for highsurface-frequency words because this effect is masked for low-surface-frequency words.

Our interpretation is that suffixed words are decomposed because in the auditory signal, the root is processed first. The integration of the last part of the stimulus allows the selection of the right candidate among all suffixed members of the morphological family. As an example, for the word jardinage, "gardening," it is the suffix-age that permits the selection of the right 
item among the other suffixed members of its family such as jardinière, "window box," jardinier, "gardener," and jardiner, "to garden." Given that in our results a cumulative frequency effect was observed only for high-surface-frequency words and that there was a surface frequency effect, we may hypothesize that the morphological family is organized on the basis of the surface frequency of each member. Each candidate corresponds to a particular combination of a root and a suffix. Thus, the most frequent members of the family would be selected before the less frequent ones. This organization of the morphological family in terms of the relative frequency of the different members could explain the absence of a cumulative frequency effect for low-frequency suffixed words. If the recognition of a suffixed word involves prior access to its root and if this root representation is sensitive to frequency, the saving of time due to the cumulative frequency effect would be neutralized by the loss of time due to the difficulty in selecting the candidate corresponding to a low-frequency member of the family. This difficulty is related to the presence in the morphological family of competitors having a higher activation than the actual target word. For example, the identification of the word jardinière could be affected by the existence of other suffixed words in the same family like jardinier or jardinage, which are more frequent than jardinière. When a word has a low cumulative frequency, access to the morphological family is slower than access to the morphological family for a higher cumulative frequency word. However, if the low-cumulativefrequency word is one of the more frequent of its family and the high-cumulative-frequency one is not, then the reaction times for these two words could be similar.

Without denying the role of the whole morphological family, our interpretation emphasizes the role of a subset of members of the family, namely those sharing their initial cohort (the suffixed members of the family). The cumulative frequency corresponding to this subset of candidates may be called the cumulative frequency of the morphological cohort. It appears that this cumulative frequency of the morpho- logical cohort is most often confounded with the cumulative frequency of the whole family. Indeed, morphological families in French are mostly composed of suffixed words, and the rare prefixed members have very low surface frequencies. This would explain why these two parameters have been conflated in the past. If we recalculate the cumulative frequency of the morphological cohort for the experimental items of Experiment 2, we observe that only 1 pair of words (out of 20) changes in category. The other pairs are unchanged. For example, équipier, "member of a team," which has a cumulative frequency of 41.8 , has a cumulative frequency of the morphological cohort of 41.5 and its matched word, gondolier, "gondolier," has a cumulative frequency of 3.3 and a cumulative frequency of the morphological cohort of 3.3.

According to the interpretation proposed above, a factor that should affect the identification process of a particular suffixed word is the number of other suffixed words of the same family having a higher frequency. In the stimuli for our second experiment, we observed that for high-surface-frequency suffixed words, there was nearly the same number of more frequent candidates for high-cumulative-frequency words (1.3 more frequent candidates) and for low-cumulative-frequency ones (1.5 more frequent candidates) $(t<1)$. For low-surface-frequency suffixed words, there was a significant difference in the number of more frequent candidates: high-cumulative-frequency words had a greater number of more frequent candidates (mean 4.5) than low-cumulative-frequency words (mean 1.9) $[t(9)=2.46, p<.04]$. These observations seem to corroborate our interpretation: for low-surface-frequency suffixed words, the saving in time due to cumulative frequency could be lost by the greater number of candidates to process before the identification of the target.

The aim of our third experiment was to test this interpretation using low-frequency suffixed words having the same number of candidates more frequent than the target and differing only in their cumulative frequency. If the absence of a cumulative frequency effect for these words in 
Experiment 2 was related to a difference in the distribution of higher frequency candidates between the two types of experimental words (high and low cumulative frequency), then control of this factor should permit the observation of a cumulative frequency effect.

\section{EXPERIMENT 3}

In this experiment, we compared lexical decision times for pairs of low-surface-frequency suffixed words matched on several parameters, including surface frequency, the number of candidates belonging to the morphological cohort, and the number of these candidates more frequent than the target. Members of each pair contrasted in terms of cumulative frequency. For instance, for the pair coiffeur, "hairdresser," and chercheur, "researcher," coiffeur has a cumulative frequency of 52, while chercheur has one of 637.

\section{Method}

Stimuli, design, and procedure. We selected 14 pairs of suffixed words. Each word pair comprised two suffixed words sharing a suffix but not the root. Within each pair we controlled duration (677 ms for words with high cumulative frequency vs $639 \mathrm{~ms}$ for words with low cumulative frequency), surface frequency (3 vs $2)$, the number of candidates in the morphological cohort (10 vs 10), and the number of cohort candidates more frequent than the target (6 vs $6)$. The two words differed only in their cumulative frequency: the mean of high-cumulativefrequency items was 485 , and the mean of lowcumulative-frequency items was 47 . The items are listed in Appendix C.

We constructed two lists of 116 items each: 28 experimental items, 30 filler words, and 58 nonwords that were, as in the other experiments, pronounceable and matched in length and morphological properties with the real words (28 "pseudosuffixed" nonwords, such as gotteur, and 30 pseudomonomorphemic nonwords, such as monle).

As in the previous experiment, each participant listened to the same experimental list that contained both words from each pair. Because the experimental pairs did not share a root, this

\section{TABLE 3}

Mean Reaction Times and Error Rates as a Function of Cumulative Frequency for Low-Frequency Suffixed Words in Experiment 3

\begin{tabular}{lrr}
\hline & \multicolumn{2}{c}{ Cumulative frequency } \\
\cline { 2 - 3 } & High & Low \\
\hline RT $(\mathrm{ms})$ & 909 & 956 \\
SD & 99 & 109 \\
Errors $(\%)$ & 4 & 13 \\
\hline
\end{tabular}

was not problematic. The second list was identical to the first one except for the order of presentation for the items of each pair. Before the experimental list we gave participants four examples of nonwords, and the first 10 items of each list were filler items. Participants were tested individually within a single experimental session. The procedure and apparatus were the same as in the other experiments. Again, we used a lexical decision task.

Participants. A total of 20 students from the same population as the other experiments participated in this one.

\section{Results and Discussion}

Reaction times higher than $1500 \mathrm{~ms}$ (2\% of all reaction times) were eliminated from the statistical analyses. Table 3 presents the mean reaction times and error rates for the two experimental conditions. Suffixed words with high cumulative frequency were responded to faster than words with low cumulative frequency. This effect was significant across participants $[F 1(1,19)=9.61 ; p<.006]$ and across items $[F 2(1,13)=4.93 ; p<.05]$. We also found a significant effect in the error analyses across participants $[F 1(1,19)=59.3 ; p<.001]$ and across items $[F 2(1,13)=13.69 ; p<.003]$. There were more errors for low-cumulativefrequency words than for high ones.

It appears that, as we suggested above, the uncontrolled features of the morphological cohort suppressed the cumulative frequency effect in Experiment 2. When factors such as the number of candidates more frequent than the target and belonging to the same morphological co- 
hort were controlled, we observed an effect of the cumulative frequency for low-surface-frequency suffixed words. Results from Experiments 2 and 3 seem compatible with the hypothesis that suffixed members of a morphological family are accessed via their root. The cumulative frequency effect in lexical decision performance for suffixed words implies that their lexical representations are accessed via the root of their morphological family. When the root is activated it also activates suffixes with which it may be combined. These different combinations then compete.

The aim of Experiment 4 was to establish the role of higher frequency morphological competitors in the identification of suffixed words. In this experiment we compared lexical decision times for pairs of suffixed words, matched on several parameters, but differing in the number of candidates belonging to the morphological cohort which had a higher surface frequency than the target. For example, durable, "durable," has three candidates of higher frequency, while jouable, "playable," has six. If, as suggested by the results of Experiment 3, the higher frequency morphological candidates slow the selection of the target word, response times should be faster for targets having few higher frequency candidates than for targets having more higher frequency candidates.

\section{EXPERIMENT 4}

\section{Method}

Stimuli, design, and procedure. We selected 14 pairs of suffixed words. Each word pair comprised two suffixed words sharing a suffix but not the root. Within each pair, we controlled the word duration (680 ms for words with many candidates in their morphological cohort more frequent than themselves vs $699 \mathrm{~ms}$ for words with few competitors), the surface frequency (1 vs 5), the cumulative frequency of the morphological cohort (129 vs 123), and the number of candidates in the cohort (10 vs 10$)$. The two words of each pair differed in the number of more frequent candidates, items with many stronger competitors averaging seven, and those
TABLE 4

Mean Reaction Times and Error Rates as a Function of Number of Candidates in the Morphological Cohort More Frequent Than the Stimulus in Experiment 4

\begin{tabular}{lrr}
\hline & \multicolumn{2}{c}{ Number of candidates } \\
\cline { 2 - 3 } & Many & Few \\
\hline RT $(\mathrm{ms})$ & 906 & 858 \\
SD & 132 & 100 \\
Errors $(\%)$ & 11 & 9 \\
\hline
\end{tabular}

with few stronger competitors averaging two. The items are listed in Appendix D.

As in Experiment 3, we constructed two lists of 116 items each: 28 experimental words, 30 filler words, and 58 nonwords. Nonwords were pronounceable and matched in length and morphological properties with the real words in the list (28 "pseudosuffixed" nonwords such as gotteur and 30 pseudomonomorphemic nonwords such as monle). As in the previous experiment, each participant heard only one list, which included both members of each pair. Participants were tested individually within a single session. The procedure and apparatus were the same as in Experiment 3. Again we used a lexical decision task.

Participants. Twenty students from the same population as the other experiments took part in this experiment.

\section{Results and Discussion}

Reaction times higher than $1500 \mathrm{~ms}$ (3\% of all reaction times) were eliminated from the statistical analyses. The items servilement and formellement were also excluded because they produced more than $50 \%$ errors.

Table 4 presents the mean RTs and error rates for the two experimental conditions. Suffixed words with fewer higher frequency competitors were identified faster than words with more higher frequency competitors. This effect was significant across participants $[F 1(1,19)=$ 14.96; $p<.001]$ and across items $[F 2(1,12)=$ 5.6; $p<.04]$. The effect was not significant in the error analyses $[F 1<1 ; F 2<1]$.

These results show an effect on reaction 
times of the number of candidates belonging to the same morphological cohort with a higher surface frequency. We can conclude that the frequency position of the target within its family is important for its identification. Thus, the important parameter is not the surface frequency itself but the relative frequency of the target compared to the frequency of the other members of its morphological family. This confirms our hypothesis: the lack of cumulative frequency effect for low-surface-frequency words observed in Experiment 2 could be due to the time required to inhibit or examine the more frequent candidates. Our results do not allow us to decide whether the extra time observed for items with more candidates was due to time spent examining or to time spent inhibiting the candidates, although according to the new version of the Cohort model (Marslen-Wilson, 1987, 1990; Marslen-Wilson, Tyler, Waksler, \& Older, 1994), this extra time should result from inhibition due to the different thresholds of each of the items. Nevertheless, our findings clearly show the existence of frequency organization within a morphological family.

\section{GENERAL DISCUSSION}

In these experiments we exploited the role played by different frequency characteristics to investigate the type of process and the form of the lexical entry for suffixed morphologically complex words. Our major findings can be summarized as follows. Experiment 1 showed that lexical decision times to suffixed words were influenced by the word's surface frequency. Experiment 2 confirmed the role of surface frequency and showed that a cumulative frequency effect was only observed for high-surface-frequency suffixed words. Experiment 3 indicated that the absence of a cumulative frequency effect for low-frequency words in Experiment 2 was due to uncontrolled features of the morphological cohort. Specifically, when the number of candidates belonging to the morphological cohort and the number of these candidates with a higher surface frequency than the target were controlled, a cumulative frequency effect was observed for low-surface-frequency suffixed words. Experiment 4 showed that lexical deci- sion times for suffixed words varied as a function of their surface frequency position in the family. Words with more higher frequency family members took longer to identify than words with fewer higher frequency family members.

We thus observed an effect of two types of frequencies for suffixed words: a surface frequency effect and a cumulative frequency effect. These indicate, respectively, an effect of the full word form and an effect of morphological structure. More importantly, the results of Experiments 3 and 4 indicate that these two factors interact in a complex manner such that the identification time for two words having identical surface and cumulative frequencies may be very different according to the frequency distributions of the other members in their morphological families.

In order to explain the observed effects, we proposed that suffixed words belonging to a given morphological family share a lexical entry corresponding to the root. This root representation is sensitive to frequency of use and affects the time to access the morphological family. This proposition accounts for the presence of a cumulative frequency effect in Experiments 2 and 3. However, in order to account of the results of Experiment 4, it is necessary to assume that a selection process, which takes time, occurs among the members of the accessed morphological family when the presented target word does not correspond to the more frequent member of this family. This selection process may be conceived in terms of a competition among morphological candidates. Figure 1 illustrates this point.

As noted in this figure, access to a suffixed word takes place at two different moments: the access to the morphological family $(t 1)$ and the access to the particular member of this morphological family $(t 2)$. This particular member corresponds to one of the possible combinations of the root and a given suffix.

This interpretation must be linked to the one expounded by Marslen-Wilson et al. (1994). These authors ran several experiments using a cross-modal auditory-visual priming task to investigate the lexical entry of morphologically complex words. They did not observe any prim- 


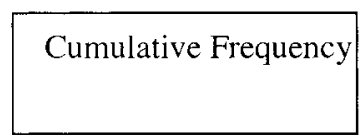

t1
Surface Frequency

of the members of the morphological cohort
12

FIG. 1. Two factors that take effect at two different times ( $t 1$ and $t 2)$ during lexical access. The numbers in parentheses indicate the frequency: the cumulative frequency of the root and the surface frequency of the derived item.

ing between two suffixed words belonging to the same morphological family. This result contrasted with the presence of a priming effect between prefixed words and between affixed words and their stems. More generally in priming experiments a clear facilitatory priming effect is found between morphologically related words (see Drews, 1996, for a review). Marslen-Wilson et al. (1994) attributed the lack of priming between suffixed words to the existence of inhibitory relations between the suffixes of the decomposed lexical entry. When the listener encounters a suffixed form, the stem will be heard first, and this will activate both the stem itself and the suffixes attached to this stem. As soon as the evidence is available to select one suffix rather than another, these suffixed competitors will be suppressed. This slows responses to one of these competitors if it is subsequently presented as a target in the priming task. The critical feature of this account is that different words share simultaneously an initial cohort and a lexical representation. Pairs like attractive and attraction are mutually exclusive in the strong sense that the same lexical representation (the stem morpheme attract) cannot simultaneously be interpreted as two different lexical items. Hearing the word attractive means that the word attraction has been eliminated as a possible candidate.
We agree with the idea that members of the same morphological cohort interact during the identification of suffixed words. The problem is that Marslen-Wilson et al. (1994) did not observe a real inhibitory effect between two suffixed words derived from the same stem. Our fourth experiment is the first conclusive demonstration of competition during the processing of suffixed words. The absence of an inhibitory effect in the cross-modal paradigm of MarslenWilson et al. (1994) could be related to the fact that in this paradigm the recognition process of the prime word has been achieved just before the presentation of the target and then the competition process is no longer functional.

We then propose that in our Experiment 4 the recognition of the target was slowed by the existence of lateral inhibitory links among the suffixed members of the family. The inhibitory power of candidates is related to their respective activation levels and to their frequency in the language. According to our interpretation, the presence of a cumulative frequency effect for suffixed words indicates that these words are accessed by their common root, in agreement with the left-to-right directionality of the speech processing. This access by the root induced the decomposition of the word into its morphological components. This proposition seems to be particularly well adapted for the processing of 
suffixed words, given that the beginning of these words makes available the essential semantic information conveyed by the root.

As noted before, the only experiment that clearly supports the hypothesis of prelexical decomposition in the auditory modality is one done with nonwords (Taft et al., 1986). Experiments using real words have produced results that are generally compatible with the hypothesis of continuous access, as proposed by the Cohort model (see Tyler et al., 1988). Although these experiments do not support the prelexical decomposition hypothesis, they do show an effect of the morphological structure of a word during auditory presentation. Recently, Wurm (1997) showed with multiple regression analyses that morphemic variables, such as prefixedness or semantic transparency, play a role during auditory identification of prefixed words, and at the same time he confirmed the importance of the surface form of this type of word.

Future experiments should be designed to confirm and define more precisely the nature of the processes underlying the inhibitory effect obtained in our Experiment 4. In particular, it is important to establish if the effects observed in this experiment can be attributed to the morphological neighborhood of the presented item rather than to its phonological one. Words sharing the same root have not only morphological but also orthographic and phonological links. Could these form links explain our effects? We do not have a definitive response at this point and more evidence is necessary to disentangle these factors. However, previous research conducted with a priming procedure has separated effects of morphological links from effects of formal ones (Fowler, Napps, \& Feldman, 1985; Marslen-Wilson et al., 1994), suggesting that these two types of links are represented in a different way in the internal lexicon.

What our research clearly shows is the existence of a morphological competition process that take place during the auditory recognition of suffixed words. This competition process occurs among the members of a morphological cohort and reflects their relative frequencies.

\section{APPENDIX A}

Test Words Used in Experiment 1 and Their Characteristics

\begin{tabular}{lclc} 
High-frequency words & Surface frequency & Low-frequency words & Surface frequency \\
\hline adversaire & 45 & adversité & 1 \\
correction & 12 & correcteur & 1 \\
destination & 9 & destinataire & 2 \\
laideur & 14 & laideron & 0 \\
vieillard & 59 & vieillerie & 2 \\
marchandise & 13 & marchandeur & 0 \\
corporel & 13 & corpulent & 1 \\
démonstration & 14 & démonstrateur & 0 \\
dignité & 41 & dignitaire & 2 \\
direction & 89 & directive & 4 \\
divinité & 18 & divination & 3 \\
froideur & 12 & froidure & 1 \\
lâcheté & 21 & lâchage & 1 \\
largeur & 10 & largesse & 2 \\
libération & 24 & libérateur & \\
littérature & 91 & littérateur & 5 \\
mariage & 100 & marieur & 14 \\
tailleur & 9 & taillade & 0 \\
travailleur & 23 & travailliste & chevalerie \\
chevalier & 33 & & 0 \\
\hline & & & 0 \\
& & \\
\end{tabular}

Note. All the frequency values listed here and in the following appendices are values per million. 


\section{APPENDIX B}

Test Words Used in Experiment 2 and Their Characteristics

Pairs of Suffixed Words with Low Surface Frequencies

\begin{tabular}{|c|c|c|c|c|c|c|c|c|c|c|c|}
\hline $\begin{array}{c}\text { Items with a } \\
\text { high } \\
\text { cumulative } \\
\text { frequency }\end{array}$ & 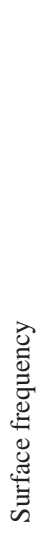 & 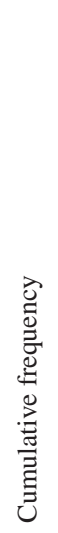 & 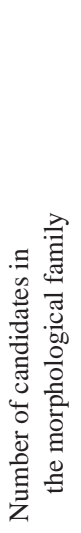 & 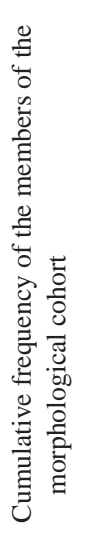 & 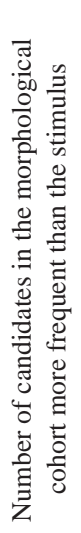 & $\begin{array}{c}\text { Items with a } \\
\text { low } \\
\text { cumulative } \\
\text { frequency }\end{array}$ & 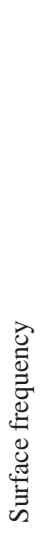 & 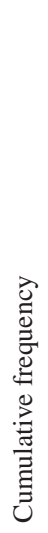 & 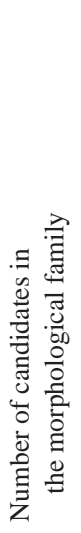 & 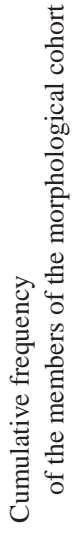 & 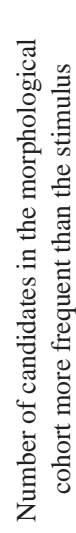 \\
\hline griffonnage & 1 & 21 & 14 & 21 & 4 & babillage & 1 & 3 & 6 & 3 & 2 \\
\hline hivernage & 1 & 96 & 7 & 96 & 2 & balayage & 1 & 37 & 9 & 37 & 5 \\
\hline raffinage & 0 & 87 & 26 & 22 & 2 & parrainage & 0 & 8 & 2 & 8 & 1 \\
\hline ricaneur & 0 & 361 & 7 & 25 & 3 & rouspéteur & 0 & 1 & 4 & 1 & 2 \\
\hline parfumeur & 1 & 69 & 6 & 69 & 4 & brocanteur & 2 & 2 & 5 & 2 & 1 \\
\hline pleurnicheur & 0 & 191 & 14 & 191 & 9 & bagarreur & 0 & 5 & 5 & 5 & 2 \\
\hline ravageur & 1 & 20 & 5 & 20 & 3 & radoteur & 1 & 2 & 5 & 2 & 2 \\
\hline poissonneux & 0 & 41 & 9 & 41 & 2 & pelucheux & 0 & 2 & 2 & 2 & 1 \\
\hline chansonnier & 1 & 361 & 25 & 305 & 11 & buissonnier & 0 & 25 & 9 & 25 & 2 \\
\hline équipier & 0 & 42 & 14 & 41 & 6 & gondolier & 1 & 3 & 6 & 3 & 1 \\
\hline
\end{tabular}

Pairs of Suffixed Words with High Surface Frequencies

\begin{tabular}{|c|c|c|c|c|c|c|c|c|c|c|c|}
\hline $\begin{array}{l}\text { Items with a } \\
\text { high } \\
\text { cumulative } \\
\text { frequency }\end{array}$ & 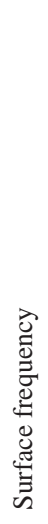 & 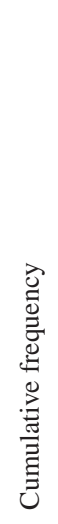 & 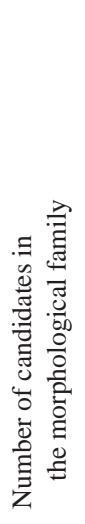 & 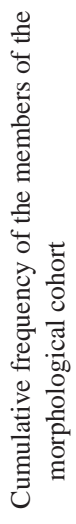 & 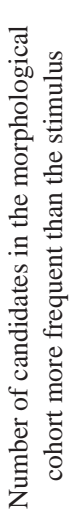 & $\begin{array}{c}\text { Items with a } \\
\text { low } \\
\text { cumulative } \\
\text { frequency }\end{array}$ & 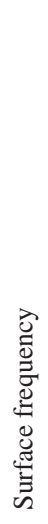 & 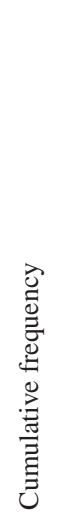 & 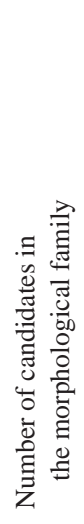 & 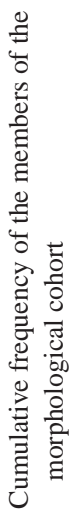 & 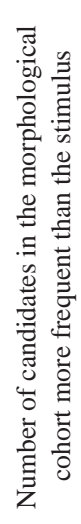 \\
\hline jardinier & 16 & 197 & 8 & 197 & 1 & policier & 11 & 64 & 6 & 64 & 1 \\
\hline travailleur & 23 & 588 & 12 & 588 & 3 & serviteur & 27 & 552 & 25 & 554 & 4 \\
\hline gouverneur & 17 & 212 & 12 & 212 & 2 & visiteur & 24 & 183 & 9 & 193 & 2 \\
\hline ténébreux & 13 & 77 & 3 & 67 & 1 & paresseux & 15 & 39 & 6 & 39 & 1 \\
\hline courageux & 15 & 183 & 15 & 118 & 1 & orgueilleux & 19 & 114 & 7 & 111 & 1 \\
\hline victorieux & 15 & 232 & 10 & 94 & 1 & respectueux & 15 & 156 & 14 & 154 & 2 \\
\hline monstrueux & 30 & 82 & 4 & 72 & 1 & prodigieux & 30 & 49 & 3 & 49 & 1 \\
\hline correction & 12 & 65 & 18 & 35 & 1 & séduction & 12 & 28 & 3 & 28 & 1 \\
\hline comédien & 12 & 52 & 2 & 52 & 1 & milicien & 9 & 12 & 2 & 12 & 1 \\
\hline voisinage & 18 & 156 & 9 & 153 & 2 & esclavage & 12 & 51 & 4 & 51 & 1 \\
\hline
\end{tabular}




\section{APPENDIX C}

Test Words Used in Experiment 3 and Their Characteristics

\begin{tabular}{|c|c|c|c|c|c|c|c|c|c|c|c|}
\hline $\begin{array}{l}\text { Items with a } \\
\text { high } \\
\text { cumulative } \\
\text { frequency }\end{array}$ & 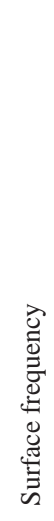 & 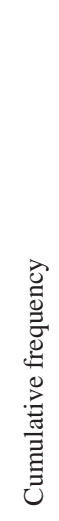 & 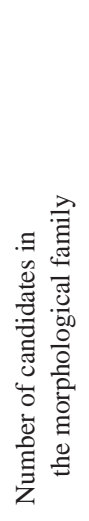 & 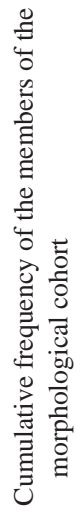 & 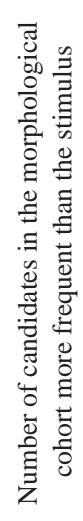 & $\begin{array}{c}\text { Items with a } \\
\text { low } \\
\text { cumulative } \\
\text { frequency }\end{array}$ & 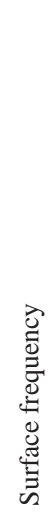 & 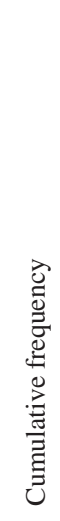 & 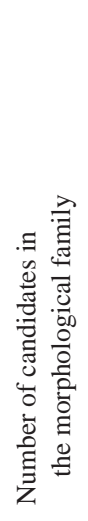 & 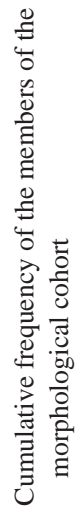 & 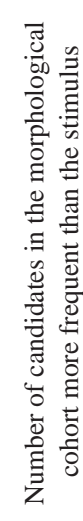 \\
\hline lessivable & 0 & 8 & 8 & 5 & 9 & gouvernable & 0 & 212 & 212 & 8 & \\
\hline narrable & 0 & 8 & 10 & 6 & 7 & jouable & 0 & 332 & 342 & 6 & 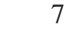 \\
\hline respectif & 5 & 154 & 156 & 5 & 11 & portatif & 2 & 485 & 1536 & 6 & 10 \\
\hline olivier & 10 & 16 & 16 & 0 & 9 & jardinier & 16 & 197 & 197 & 0 & 8 \\
\hline bouchage & 0 & 16 & 60 & 5 & 7 & bordage & 1 & 183 & 682 & 5 & 7 \\
\hline brouillage & 0 & 69 & 93 & 7 & 13 & comptage & 0 & 405 & 416 & 12 & 13 \\
\hline crachotement & 0 & 31 & 31 & 10 & 12 & chantonnement & 1 & 305 & 317 & 10 & 13 \\
\hline griffement & 0 & 21 & 20 & 13 & 14 & croisement & 4 & 207 & 162 & 9 & 16 \\
\hline polémiste & 1 & 7 & 7 & 2 & 5 & travailliste & 0 & 588 & 588 & 5 & 8 \\
\hline dotation & 1 & 20 & 20 & 3 & 5 & perdition & 4 & 512 & 476 & 4 & 5 \\
\hline griffeur & 0 & 21 & 20 & 10 & 14 & grosseur & 3 & 364 & 366 & 8 & 15 \\
\hline cueilleur & 0 & 26 & 26 & 4 & 7 & toucheur & 1 & 266 & 275 & 4 & 7 \\
\hline coiffeur & 9 & 49 & 52 & 3 & 8 & chercheur & 6 & 511 & 637 & 3 & 4 \\
\hline classable & 0 & 129 & 134 & 9 & 14 & serviable & 2 & 554 & 572 & 7 & 14 \\
\hline
\end{tabular}

\section{REFERENCES}

Andrews, S. (1986). Morphological influences on lexical access: Lexical or nonlexical effects? Journal of Memory and Language, 25, 726-740.

Bates, E., Devescovi, A., Pizzamiglio, L., D’Amico S., \& Hernandez, A. (1995). Gender and lexical access in Italian. Perception and Psychophysics, 57, 847-862.

Bradley, D. C. (1979). Lexical representation of derivational relation. In M. Aronoff \& M. L. Kean (Eds.), Juncture (pp. 37-55). Sarasota, CA: Anma Libri.

Broadbent, D. E. (1967). Word-frequency effect and response bias. Psychological Rewiew, 74, 504-506.

Burani, C., \& Caramazza, A. (1987). Representation and processing of derived words. Language and Cognitive Processes, 2, 217-227.

Colé, P., Beauvillain, C., \& Segui, J. (1989). On the representation and processing of prefixed and suffixed derived words: A differential frequency effect. Journal of Memory and Language, 28, 1-13.

Connine, C. M., Titone D., \& Wang J. (1993). Auditory word recognition: Extrinsic and intrinsic effects of word frequency. Journal of Experimental Psychology: Learning, Memory, and Cognition, 19, 81-94.

Connine, C. M., Mullenix, J., Shernoff, E., \& Yelen, J. (1990). Word familiarity and frequency in visual and auditory word recognition. Journal of Experimental Psychology: Learning, Memory, and Cognition, 16, 1084-1096.

Cutler, A., Hawkins, J. A., \& Gilligan, G. (1985). The suffixing preference: A processing explanation. Linguistics, 23, 723-758.

Drews, E. (1996). Morphological Priming. Language and Cognitive Processes, 11, 629-634.

Ferreira, F., Henderson, J. M., Anes, M. D., Weeks, P. A., \& McFarlane, D. K. (1996). Effects of lexical frequency and syntactic complexity in spoken-language comprehension: Evidence from the auditory movingwindow technique. Journal of Experimental Psychology: Learning, Memory, and Cognition, 22, 324-335.

Fowler, C. A., Napps, S. E., \& Feldman, L. B. (1985). Relations among regular and irregular morphologically related words in the lexicon as revealed by repetition priming. Memory and Cognition, 13, 241-255. 


\section{APPENDIX D}

Test Words Used in Experiment 4 and Their Characteristics

Items

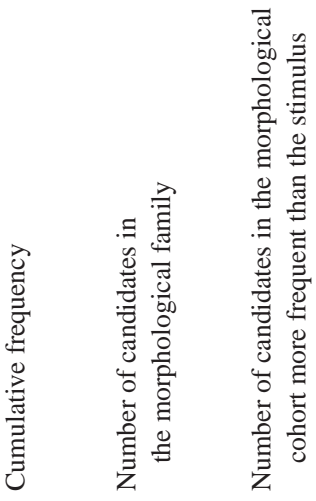

Items

$\begin{array}{lrrrr}\text { pleureur } & 2 & 191 & 12 & 4 \\ \text { brocanteur } & 1 & 2 & 5 & 1 \\ \text { polisseur } & 0 & 27 & 8 & 2 \\ \text { gazouillement } & 0 & 3 & 6 & 2 \\ \text { crachement } & 0 & 31 & 12 & 5 \\ \text { branchage } & 3 & 83 & 13 & 0 \\ \text { gaspillage } & 3 & 9 & 5 & 0 \\ \text { ordurier } & 1 & 18 & 4 & 0 \\ \text { chiffrable } & 0 & 38 & 7 & 3 \\ \text { formellement } & 6 & 613 & 16 & 6 \\ \text { chanteur } & 15 & 305 & 13 & 4 \\ \text { respectable } & 10 & 154 & 11 & 3 \\ \text { durable } & 14 & 222 & 8 & 3 \\ \text { outrage } & 9 & 27 & 10 & 0\end{array}$

$\begin{array}{llrrr}\text { coupeur } & 1 & 175 & 13 & 9 \\ \text { bafouilleur } & 1 & 6 & 6 & 4 \\ \text { lessiveur } & 0 & 8 & 9 & 7 \\ \text { flagellement } & 0 & 3 & 7 & 6 \\ \text { griffement } & 0 & 21 & 14 & 13 \\ \text { brouillage } & 1 & 69 & 13 & 7 \\ \text { nettoyage } & 4 & 22 & 5 & 2 \\ \text { couturier } & 3 & 26 & 6 & 3 \\ \text { logeable } & 1 & 72 & 8 & 7 \\ \text { servilement } & 1 & 554 & 14 & 11 \\ \text { compteur } & 2 & 405 & 13 & 7 \\ \text { observable } & 2 & 75 & 8 & 6 \\ \text { jouable } & 1 & 332 & 7 & 6 \\ \text { balayage } & 1 & 37 & 9 & 5\end{array}$

Forster, K., \& Chambers, S. M. (1973). Lexical access and naming time. Journal of Verbal Learning and Verbal Behavior, 12, 627-635.

Geffen, G., Stierman, I., \& Tildesley, P. (1979). The effect of word length and frequency on articulation and pausing during delayed auditory feedback. Language and Speech, 22, 191-199.

Henderson, L. (1985). Toward a psychology of morphemes. In A. W. Ellis (Ed.), Progress in the psychology of language (pp. 15-72). London: Erlbaum.

Holmes, V. M., \& O'Regan, J. K. (1992). Reading derivationally affixed French words. Language and Cognitive Processes, 7, 163-192.

Howes, D. (1957). On the relationship between intelligibility and frequency of occurrence of English words. Journal of the Acoustical Society of America, 29, 296305.

Howes, D., \& Solmon, R. L. (1951). Visual duration thresholds as a function of word probability. Journal of Experimental Psychology, 41, 401-410.

Humphreys, G. W., Besner, D., \& Quinlan, P. T. (1988). Event perception and the word repetition effect. Journal of Experimental Psychology: General, 117, 51-67.
Jacoby, L. L., \& Dallas, M. (1981). On the relationship between autobiographical memory and perceptual learning. Journal of Experimental Psychology: General, 110, 306-340.

Landauer, T. K., \& Streeter, L. A. (1973). A structural difference between common and rare words: Failure of equivalence assumptions for theories of word recognition. Journal of Verbal Learning and Verbal Behavior, 12, 119-131.

Laudanna, A., Burani, C., \& Cermele, A. (1994). Prefixes as processing units. Language and Cognitive Processes, 9, 295-316.

McQueen, J., \& Cutler, A. (1998). Morphology in Word Recognition. In A. Spencer, \& A. Zwiky (Eds.), The handbook of morphology (pp. 406-428). Oxford: Blackwell.

Marslen-Wilson, W. D. (1987). Functional parallelism in spoken word-recognition. Cognition, 25, 71-102.

Marslen-Wilson, W. D. (1990). Activation, competition and frequency in lexical access. In G. Altmann (Ed.), Cognitive models of speech processing: Psycholinguistic and computational perspectives (pp. 148-172). Cambridge: MA: MIT Press. 
Marslen-Wilson, W. D., \& Welsh, A. (1978). Processing interactions and lexical access during word recognition in continuous speech. Cognitive Psychology, 10, 29-63.

Marslen-Wilson, W. D., Tyler, L. K., Waksler, R., \& Older, L. (1994). Morphology and meaning in the English mental lexicon. Psychological Review, 101, 3-33.

McClelland, J., \& Rumelhart, D. E. (1981). An interactive activation model of context effects in letter perception: I. An account of basic findings. Psychological Review, 88, 375-407.

Meunier, F. (in press). Morphologie et traitement du langage parlé. Presses Universitaires du Septentrion. Villenueve d'Ascq, France.

Morton, J. (1969). Interaction of information in word recognition. Psychological Review, 76, 165-178.

Morton, J. (1982). Disintegrating the lexicon. In J. Mehler, E. T. C. Walker, \& M. Garrett (Eds.), Perspectives in mental representation (pp. 89-109). Hillsdale, NJ: Erlbaum.

Oldfield, R. C., \& Wingfield, A. (1965). Response latencies in naming objects. The Quarterly Journal of Experimental Psychology, 17, 273-281.

Pollack, I., Rubenstein, H., \& Decker, L. (1960). Analysis of the correct responses to an unknown message set. Journal of the Acoustical Society of America, 32, 454-457.

Rey-Debove, J. (1984). Le domaine de la morphologie lexicale. Cahiers de Lexicologie, 45, 3-19.

Rey-Debove, J. (1989). Le Robert méthodique: Dictionnaire méthodique du français actuel. Dictionnaires Le Robert (Eds.), Paris.

Rubenstein, H., Garfield, L., \& Millikan, J. (1970). Homographic entries in the internal lexicon. Journal of Verbal Learning and Verbal Behavior, 9, 487-494.

Savin, H. (1963). Word frequency effects and error in the perception of speech. Journal of the Acoustical Society of America, 35, 200-206.

Schriefers, H., Zwitserlood, P., \& Roelofs, A. (1991). The identification of morphologically complex spoken words: Continuous processing or decomposition? Journal of Memory and Language, 30, 26-47.

Segui, J., Mehler, J., Frauenfelder, U., \& Morton, J. (1982). The word frequency effect and lexical access. Neuropsychologia, 20, 615-627.

Segui, J., \& Zubizaretta, M.-L. (1985). Mental representation of morphologically complex words and lexical access. Linguistics, 23, 759-767.
Slowiaczeck, L. M., \& Pisoni, D. B. (1986). Effects of phonological similarity on priming in auditory lexical decision. Memory and Cognition, 14, 230-237.

Taft, M., \& Forster, K. I. (1975). Lexical storage and retrieval of prefixed words. Journal of Verbal Learning and Verbal Behavior, 14, 638-647.

Taft, M. (1979). Recognition of affixed words and the word frequency effect. Memory and Cognition, 7, 263-272.

Taft, M. (1981). Prefix stripping revisited. Journal of Verbal Learning and Verbal Behavior, 20, 289-297.

Taft, M. (1985). The decoding of words in lexical access: A review of the morphographic approach. In D. Besner, T. G. Waller, \& G. E. Mackinnon (Eds.), Reading research: Advances in theory and practice (pp. 83119). London: Academic Press.

Taft, M., \& Hambly, G. (1986). Exploring the Cohort Model of spoken word recognition. Cognition, 22, 259-282.

Taft, M., Hambly, G., \& Kinoshita, S. (1986). Visual and auditory recognition of prefixed words. Quaterly Journal of Experimental Psychology, 38A, 351-366.

Trésor de la Langue Française (1971). Nancy, France: Centre National de la Recherche Scientifique.

Tyler, L. K. (1984). The structure of the initial cohort: Evidence from gating. Perception and Psychophysics, 36, 417-427.

Tyler, L. K., Marslen-Wilson, W., Rentoul, J., \& Hanney, P. (1988). Continuous and discontinuous access in spoken word-recognition: The role of derivational prefixes. Journal of Memory and Language, 27, $368-381$.

Warren, P., \& Marslen-Wilson, W. (1987). Continuous uptake of acoustic cues in spoken word recognition. Perception and Psychophysics, 41, 262-275.

Wright, C. E. (1979). Duration differences between rare and common words and their implications for the interpretation of word frequency effects. Memory and Cognition, 7, 411-419.

Wurm, L. H. (1997). Auditory processing of prefixed English words is both continuous and decompositional. Journal of Memory and Language, 37, 438-461.

(Received March 16, 1998)

(Revision received January 26, 1999) 